This paper is published in the open archive of Mid Sweden University

DIVA http://miun.diva-portal.org

with permission of the publisher

Citation for the peer-reviewed published paper:

Fjellström H, Höglund H, Forsberg S, Paulsson M, Rundlöf M. A novel method of studying the ability of coating layer to retard the photo-yellowing of the base paper. ; Nordic Pulp \& Paper Research Journal. 2007;22(3):343-349.

URL to article at publishers site:

http://dx.doi.org/10.3183/NPPRJ-2007-22-03-p343-349 


\title{
A novel method of studying the ability of a coating layer to retard the photo-yellowing of the base paper
}

\author{
Helena Fjellström, Hans Höglund and Sven Forsberg, Mid Sweden University, Sundsvall, Sweden, Magnus Paulsson, Eka Chemicals AB, Bohus, \\ Sweden, Mats Rundlöf, AB Capisco, Norrköping, Sweden
}

KEYWORDS: High-yield pulp, CTMP, Birch, Coating, pigments, Titanium dioxide, Light-induced, Ageing, Kaolin, Calcium carbonate, Fluorescent whitening agent

SUMMARY: This paper presents a method of studying the reflectance/transmittance properties of thin coating layers in relation to their inhibition of light-induced yellowing. The ability of a coating layer to retard the photo-yellowing of a hydrogen-peroxide-bleached birch chemithermomechanical pulp (CTMP) is exemplified using the developed model system. The repeatability of the method is shown to be excellent, even for coat weights below $10 \mathrm{~g} / \mathrm{m}^{2}$. Furthermore, transmittance in the UV-region is shown to be strongly correlated with a coating layer's ability to protect birch CTMP against photo-yellowing.

\begin{tabular}{l}
\hline ADDRESSES OF THE AUTHORS: Helena Fjellström \\
(helena.fjellstrom@miun.se), Hans Höglund (hans.hoglund@ \\
miun.se) and Sven Forsberg (sven.forsberg@miun.se): Mid \\
Sweden University, Fibre Science and Communication Net- \\
work, FSCN, Department of Natural Science, Holmgatan 10, \\
SE-85170 Sundsvall, Sweden. Magnus Paulsson (magnus. \\
paulsson@eka.com): Eka Chemicals AB, SE-44580 Bohus, \\
Sweden. Mats Rundlöf (mats@capisco.se): AB Capisco, \\
Nygatan 13, SE-602 34 Norrköping, Sweden. \\
Corresponding author: Helena Fjellström
\end{tabular}

The rapid brightness reversion ("yellowing"/darkening) that occurs upon exposure to daylight or indoor illumination is the major obstacle to the use of mechanical or chemimechanical pulps in high-quality long-life paper products. It is generally accepted that it is the lignin component that is responsible for the brightness reversion when the paper is subjected to sunlight or indoor illumination containing UV-radiation. In addition, additives like FWA and binders also can contribute to the brightness reversion. It has previous been reported that fluorescent whitening agents are capable of inhibiting the light-induced yellowing of lignin-containing papers (Bourgoing, Robert 1997; Bourgoing et al. 2001; Ragauskas et al. 2001). UV radiation can, however, degrade the fluorescent whitening agent, thus rendering the paper more yellowish with time (Rohringer, Fletcher 1996; Paulsson, Ragauskas 1998a).

Over the years, there have been a number of attempts to inhibit or slow down the light-induced yellowing of lignocellulosic materials. One approach has involved chemical modification of the reactive structures in lignin to suppress the formation of chromophores. Chemicals such as $\mathrm{NaBH}_{4}$ have been used to reduce the $\alpha$-carbonyl groups in lignin model compounds, milled wood lignins and different types of high-yield pulps (Leary 1968; Lin, Kringstad 1970; Ek et al. 1990; Fornier de Violet et al. 1989; Francis et al. 1991; Schmidt, Heitner 1991; Paulsson et al. 1995). Another approach has involved the use of processes such as methylation, acetylation and propionylation to etherify and/or esterify phenolic and benzylic hydroxyl groups (Schmidt, Heitner 1991; Ek et al. 1992; Paulsson, Parkås 2000; Paulsson, Simonson 2002). A variety of additives have also been investigated, ranging from UV-absorbing compounds such as benzophenone derivatives to fluorescent whitening agents (FWAs), antioxidants, polymers and quenchers (Kringstad 1969; Janson, Forsskåhl 1989, 1996; Agnemo et al. 1991; Heitner 1993a; Paulsson, Ragauskas 1998a and references cited therein; Cole et al. 2000; Bourgoing et al. 2001; Ragauskas et al. 2001). None of these approaches have yielded a cost-efficient, technically feasible and non-toxic solution to the problem of rapid yellowing. Detailed information about the mechanism of yellowing and the proposed stabilisation methods can be found elsewhere (Gratzl 1985; Heitner 1993b; Leary 1994; Davidson 1996; Forsskåhl 2000; Lanzalunga, Bietti 2000).

Today, differences in the quality of different types of wood-containing and wood-free printing and writing paper are being reduced and more paper is being coated to enhance the quality of print and images. The amount and type of pigments used in coatings vary from relatively low-cost natural mineral pigments (e.g. kaolin clay, talc, calcium carbonate) to synthetic inorganic or organic products (e.g., plastic and silica products). Coating of paper is probably necessary for adequate photostability if pulps containing lignin are to be used as the main fibre-furnishing component in long-life and high-value products. It is well-known that factors such as pigment type, pigment size distribution, coat weight, coating additives, and the homogeneity of the coating layer greatly influence photostability (Fossum et al. 1976; Gellerstedt et al. 1983; Lindblad et al. 1989; Johnson 1989, 1991; El-Sadi et al. 2002; Ghosh et al. 2002; Yuan et al. 2003). Fossum et al. (1976) showed that a $10-15 \mathrm{~g} / \mathrm{m}^{2}$ coating layer containing clay on each side of a base paper (spruce; 70\% TMP, 30\% sulphite) is somewhat more effective in retarding accelerated (xenon lamp) light-induced yellowing than a coating layer with calcium carbonate pigments. If $15 \%$ of the clay is substituted with $\mathrm{TiO}^{2}$, the yellowing is retarded even more. According to Johnson (1991), a coat weight of $\sim 4 \mathrm{~g} / \mathrm{m}^{2}$ of clay gives $20 \%$ brightness stabilisation efficiency against light-induced yellowing compared to an uncoated paper. This efficiency could be improved by substituting parts of the clay with $\mathrm{TiO}_{2}$; clay/ $\mathrm{TiO}_{2}(95: 5)$ gives a $40 \%$ brightness stabilisation efficiency, clay/ $\mathrm{TiO}_{2}$ (90:10) a $50 \%$ brightness stabilisation efficiency, and clay $/ \mathrm{TiO}_{2} \quad(80: 20)$ a $60 \%$ brightness stabilisation efficiency. The base paper in Johnson's study consisted of aspen CTMP and was coated using lick-coating 
laboratory equipment. The stabilisation effects were evaluated using two Sylvania 275 W RSM sunlamps. Yuan et al. (2003) reported that after 90 days of exposure to office light (eight $8 \mathrm{~W}$ cool-white fluorescent lamps), a coated (calcium carbonate/kaolin, $9 \mathrm{~g} / \mathrm{m}^{2}$ ) paper produced from alkaline peroxide mechanical pulp lost 2.8 ISO brightness points when $0.67 \% \mathrm{TiO}_{2}$ and $0.18 \% \mathrm{RS}$ (hydroxylamine radical scavenger) were added to the coating colour, compared to a loss of 7.0 points for the coated control.

To facilitate the optimisation of a coating formulation, especially for low coat weights, a fast and reproducible method for evaluating photostabilising effects needs to be developed. The present paper describes a reproducible method of studying the reflectance/transmittance properties at low coat weights. It also provides an example of the use of the method to evaluate the ability of a coating layer to retard the photo-yellowing of a hydrogenperoxide-bleached birch chemithermomechanical paper.

\section{Materials and Methods}

\section{Pulp samples}

A hydrogen-peroxide-bleached birch chemithermomechanical pulp, CTMP $\left(2 \% \mathrm{NaOH}, 3 \% \mathrm{Na}_{2} \mathrm{SO}_{3}\right)$, with a brightness of $79.3 \%$ ISO and a freeness of $400 \mathrm{ml} \mathrm{CSF}$ was used as base paper. Commercially produced elemental chlorine free (ECF)-bleached birch kraft pulp with an ISO brightness of 85.0 was used as a reference in the photo-ageing studies. Both pulps were manufactured at SCA Östrand, Sweden.

\section{Preparation of paper sheets}

Paper sheets with a grammage of $70 \mathrm{~g} / \mathrm{m}^{2}$ were produced on a small experimental paper machine (XPM, MoRe Research, Örnsköldsvik, Sweden) with a head box width of $0.225 \mathrm{~m}$ and a machine speed of $0.5-3.0 \mathrm{~m} / \mathrm{min}$. The fibre furnish consisted of $100 \%$ birch CTMP. The filler (Syndcarb F0474-MJ, PCC; Omya AB) content of the paper sheets was $20 \%$. The Hydrocol system (Hydrocol $878,0.01 \%$; Hydrocol SH, 0.06\%, Ciba Specialty Chemicals) was used as the retention system, and ASA was used as internal size; (Kemsize 200, 0.08\%, Sellukem). The starch for the wet-end (Raiso R142, $0.50 \%$; Raiso Chemicals) was splitted; $0.3 \%$ was added to the stock and $0.2 \%$ to the ASA. The produced papers were surface sized (C* size 05962, 2.86\%, Cerestar) and had an ISO brightness of $79.3 \%$.

\section{Coating procedure}

In order to study the transmittance and reflectance properties of thin coating layers in a reproducible way, quartz glass plates were coated in a laboratory coater using a glass rod to spread the coating colour. The speed of the rod was varied to obtain various coat weights. The coating layers were dried at room temperature before UVVIS spectroscopic analysis.

The base coating consisted of a pigment (100 parts), styrene butadiene latex (8 parts, DL920, Dow) and carboxymethylcellulose (0.5 parts, FF10, Noviant). The $\mathrm{pH}$ of the coating colour was adjusted to 8.5. The pigments used were kaolin (Supragloss 95, Imerys) or a ground calcium carbonate, GCC, (Carbital 90, Imerys). Titanium dioxide $\left(\mathrm{TiO}_{2}\right.$, rutile, Kronos 2063, Kronos) was added to the coating colour as photostabilising additive in some experiments. The coat weight was determined by scraping off the coating layer from the quartz glass on a well defined area, corresponding to the spot where the optical measurements were made, and weighing the removed material after drying in $105^{\circ} \mathrm{C}$. The coat weight is given in $\mathrm{g} / \mathrm{m}^{2}$.

\section{UV-VIS spectroscopy}

As for the majority of optical instruments, the measured values are not the total amount of light reflected or transmitted in every direction, but a well defined fraction of it. To account for the specific conditions set by the instrument and the procedures, the optical values are referred to as transmittance factors or reflectance factors.

UV-VIS spectra were recorded on a UV-Visible spectrophotometer (Varian Cary 100 Bio.) Spectral data were obtained by changing the wavelength of the illumination from $200-700 \mathrm{~nm}$ in steps of $1 \mathrm{~nm}$. The scan rate was $600 \mathrm{~nm} / \mathrm{min}$. The resulting spectra for each sampling point are mean values from at least 3 measurements.

The transmittance factors were measured in two ways:

1. a straightforward approach where the sample was placed in the cuvette holder of the spectrometer,illuminated with a single light beam at $0^{\circ}$ to the normal of its surface, in case of coated samples with the bare glass surface facing the beam. The detector was situated on the other side of the sample, directly opposite to the incoming beam, thus giving a direct measurement of the transmitted light in that direction. Zero/baseline correction was used to calibrate the instrument: a measurement in air only, with no sample in the beam, gave a $100 \%$ transmittance scan, the beam was then completely blocked to collect a $0 \%$ transmittance baseline.

2. a $0 \%$ geometry. The spectrophotometer was equipped with a 70-mm diameter integrating sphere coated with Spectralon ${ }^{\circledR}$ (DRA-CA-301). The light came into the sphere through an opening on the side, at the "equator". The quartz glass sample was placed over this opening, so that the illuminating light passed through the sample before entering the sphere. The sample was illuminated at $0^{\circ}$ to the normal, and the bare glass surface of the coated samples was facing the beam. The detector was placed at the bottom of the sphere (corresponding to the south pole) thus collecting most of the light which was transmitted through the sample in all directions. Another opening in the sphere was covered with a Spectralon ${ }^{\circledR}$ diffuse white standard (Labsphere)

Diffuse reflectance factors were measured in a similar way $(0 \%$ d). The sample was placed over an opening in the sphere directly opposite to the opening for the incoming illumination, which means that the sample was 
illuminated at $0^{\circ}$ to the normal of its surface. In this case the coating layer was facing the beam and a black or white background was used since all samples are transparent to some degree. A pile of Tyvek ${ }^{\circledR}$ (DuPont) was used as white background and black velvet was used as black background with the front side facing the sample. Diffuse detection took place as above. Baseline correction was used for calibration; a 100\% reflectance baseline was collected by measuring a Spectralon ${ }^{\circledR}$ diffuse white standard (Labsphere)

The mean value of the transmittance factors, $T$, between 300-385 nm was chosen to represent the ability of the coatings to block light in the UV region of the spectrum. The transmittance of the uncoated quartz glass plates determined in this way was in the range of 9093\%.

To evaluate the coatings, the transmittance properties were determined for a plate of quartz glass, a coating was then applied to this quartz glass and the same measurement procedure followed. The transmittance factor of the coating layer as such, $T_{C}$, was calculated by dividing the transmittance factor $(300-385 \mathrm{~nm})$ of the coated quartz glass plate, $T_{G C}$, by the transmittance factor (300-385 nm) of the bare glass plate, $T_{G}$. This is motivated by the fact that $T_{G C}$ is defined as the ratio of the transmitted intensity $I_{G C}$ and the illumination $I_{0}$, (multiplied by 100 to be expressed in \%) and in the same way for the quartz glass, $T_{G}=I_{G} / I_{0}$. Considering that in the case of a coating layer on the backside of the glass, the intensity reaching the coating layer is that transmitted through the glass, $I_{G}$, and that the intensity transmitted through the coating is $I_{G C}$, the transmittance of the coating layer, $T_{C}$, becomes $I_{G C} / I_{G}$ $=T_{G C} I_{0} / T_{G} I_{0}=T_{G C} / T_{G}$

\section{Accelerated light-induced ageing}

The accelerated ageing of the paper samples was performed with a Xenotest 150 (Heraeus, Hanau, Germany) equipped with a xenon lamp and with filters (ultraviolet and window glass) that eliminate radiation of wavelengths below $310 \mathrm{~nm}$. The temperature was kept close to room temperature by means of a cooling fan. To compensate for possible main voltage fluctuations and lamp ageing, an optical sensor controlled the irradiance. The irradiance in the UV-A region was about $40 \mathrm{~W} / \mathrm{m}^{2}$. The spectral characteristics of the transmitted light are similar to those of average indoor daylight that is, of sunlight through window glass (Paulsson, Ragauskas 1998b).

\section{Standard Optical measurements}

ISO brightness of the paper samples was measured using an Elrepho SE 071 spectrophotometer (Lorentzen \& Wettre) in accordance with ISO standard method 2470. An opaque pile of unaged base paper was used as background.

\section{Determination of $\mathbf{s}$ and $\boldsymbol{k}$-values for the coatings}

The calculation of $s$ and $k$ require two different values of the reflectance factor at the particular wavelength, which may be values measured on a single layer (or sheet) over two different backgrounds, not necessarily a completely black and a very white background (Karipidis 1994). In this work, the reflectance factor measured on the assembly of quartz glass coated with the layer of the lowest coat weight over a black or white backing was used as "background"-value in the calculations (Fig 1). The sample, coated with a thicker layer of the same coating colour was then measured over black and white. This means that effectively $\mathrm{s}$ and $\mathrm{k}$ were estimated for $\mathrm{a}$ "coating layer" of a coat weight corresponding to the difference between the thicker coating of the sample and the thin coating on the glass used as background. This was done to decrease the possible geometric effects of measuring a background covered by a glossy glass surface, while the coated sample has a less glossy surface and scatter light more diffusely.

Using this approach, $s$-values were determined over the spectrum. At shorter wavelengths, the calculations did not give correct values, probably because of too strong absorption (see e.g. Rundlöf, Bristow 1997). A linear extrapolation was therefore made from data at longer wavelengths, and the $s$-values in the UV region could be estimated. These approximate $s$-values were used to calculate the corresponding values of $k$ together with the calculated $R_{\infty}$, which was similar to the measured values since the background has little or no effect in the case of strong absorption.

Calculations of $\mathrm{s}$ and $k$-values were also made from transmittance factors measured using the integrating sphere and reflectance factors over the black background. Here, the presence of the quartz glass was ignored, and the measured values were used directly. Calculations were made at one wavelength, $350 \mathrm{~nm}$, using the equations given by Karipidis (1994 and references therein). The equation for the calculation of the transmittance factors at different coat-weights from values of $\mathrm{s}$ and $k$ are derived from the same source.

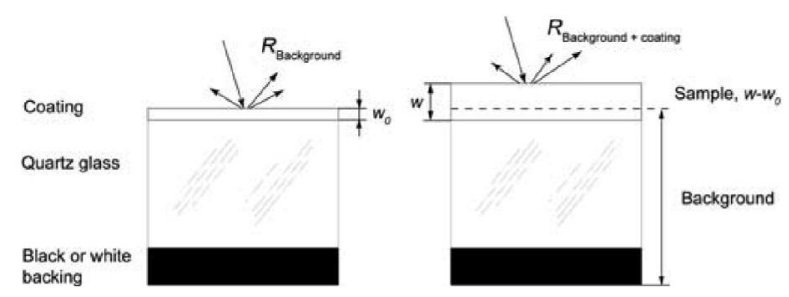

Fig 1. Definition of "background" and "sample" in the calculations of $s$ and $k$-values

\section{Results and Discussion}

\section{Development of a method to evaluate the photo- stabilising properties of coating layers}

A number of problems have to be overcome in order to study how different properties of a coating, pigments, particle size distributions, coat weights and coating additives influence the brightness stability of a coated paper. For one thing, the high surface roughness and high water absorption of high-yield mechanical or chemimechanical pulps mean that at low coat weights the surface coverage may be uneven. For another, when studying 


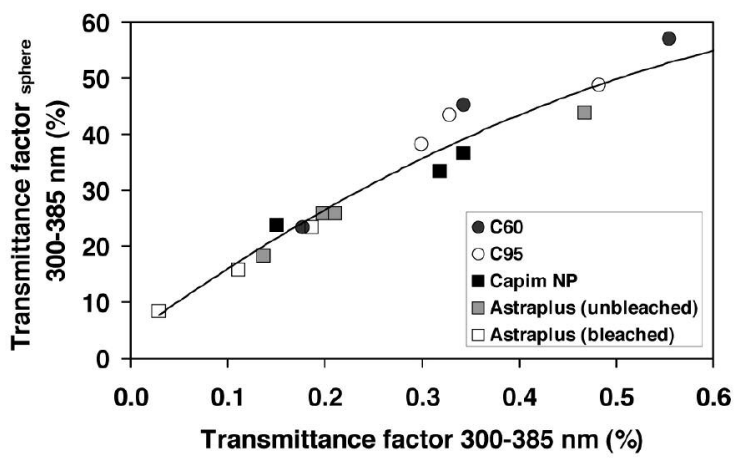

Fig 2. Mean transmittance factors in the UV region between $300-385 \mathrm{~nm}$, obtained using an integrating sphere for detection of the diffusely transmitted light and by detecting the transmitted light directly opposite to the illumination at narrow angles to the normal of the sample.

a coated paper, it is impossible to distinguish changes caused by photo-yellowing of the coating layer from changes caused by photo-yellowing of the base paper.

These problems are addressed in the present method by the use of coated quartz glass plates, enabling the coat weight and the reflectance/transmittance properties of the coating layer to be measured on exactly the same coated area. Very thin, uniform coating layers can be deposited on these plates. The experimental procedure has the further advantage that it is fast and simple.

The quartz glass is highly transparent also in the UVregion of the spectrum. The optical properties of the quartz glass are easily measured, and can be compensated for to estimate the transparency of the coating layer as such from data measured on coated glass. The coated samples were illuminated at $0^{\circ}$ to the normal of the surface by a beam of light. The wavelength of the illumination was scanned over the UV-VIS spectrum. Two geometries for detecting the transmitted light were tested: i) $0 \% \mathrm{~d}$, an integrating sphere placed behind the sample, which collects most of the light transmitted in all directions ii) $0^{\circ} / 0^{\circ}$, using the detector of the spectrophotometer placed behind the sample, directly opposite to the light source, collecting transmitted light only at narrow angles to the normal of the surface.

Fig 2 shows a comparison between the two methods, the values presented are a mean of the data collected in the UV-region between 300 and $385 \mathrm{~nm}$ in wavelength. As expected, the transmittance factors obtained using the integrating sphere, $\mathrm{T}_{\text {sphere }}$, were much higher than those measured in the direction of the illumination only $\left(0^{\circ} / 0^{\circ}\right)$ where the diffusely transmitted light is excluded. There was however a good correlation between them, which shows that the transmittance factor measured in the direction of the illumination can be used to represent the overall transmittance of the samples at least for the investigated range of coat-weights. Based on this fact, the straight forward measurement using a single beam was chosen for further studies.

An attempt was made to estimate the light scattering and light absorption coefficients, $s$ and $k$, of a coating layer in the UV-region of the spectrum. This was done in two ways: from the measured reflectance factors over a black and a white background and from the transmittance

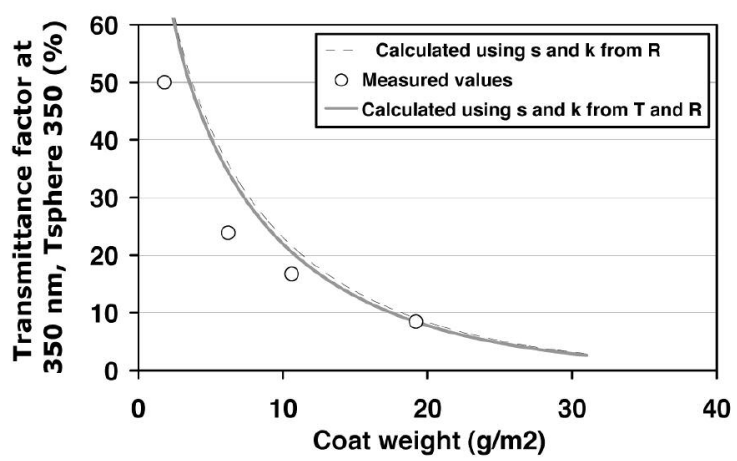

Fig 3. Calculated and measured values of the transmittance factor at $350 \mathrm{~nm}$ as a function of coat weight for one of the clays (bleached Astraplus).

factors obtained using the sphere. For one of the clay coatings shown in Fig 1 (bleached Astraplus, $19.2 \mathrm{~g} / \mathrm{m}^{2}$ ), the $s$-value at $350 \mathrm{~nm}$ was estimated to $225 \mathrm{~m}^{2} / \mathrm{kg}$ (from reflectance data) and $240 \mathrm{~m}^{2} / \mathrm{kg}$ (using transmittance data in addition), the $k$-values were 19.5 and $19.3 \mathrm{~m}^{2} / \mathrm{kg}$ respectively. The $s$-values are in fair agreement with those reported by Karipidis (1994) for a clay coating, considering the fact that $\mathrm{s}$ increases with decreasing wavelength, and that different instruments and sample preparations were used. The values of $k$ were higher than those normally obtained at visible wavelenghts, which is probably due to that many materials absorb UV-light to a higher extent than visible light. Thus, it seems to be possible to get reasonable estimates of $s$ and $k$ in the UV region from these data. These $s$ and $k$ values were used as a starting point to calculate the transmittance factor as a function of coat weight using the Kubelka-Munk equations (Karipidis 1994). Fig 3 shows the calculated relations (solid and broken lines) and the measured transmittance factors using the sphere (open symbols). Despite the fact that several approximations were involved in estimating $s$ and $k$ from reflectance data, there is a good agreement between measurement and calculation at $19 \mathrm{~g} / \mathrm{m}^{2}$. Further, this experimental curve, and the other measured values presented, shows the same non-linear shape as the calculated curves.

Deviations of measured values from the calculated values at low coat weights has been observed and discussed by e.g. Karipidis (1994). When calculating $s$ and $k$ for coatings, the values often seem to change with coat weight, especially in the lower range, so that the agreement could probably be improved if $s$ and $k$ were determined separately for each coat-weight. This is however beyond the scope of this work.

This experimental method also facilitates studying the coating layer separately from the base paper before and after photo-ageing to determine the extent to which it protects the base paper, a schematic presentation is given in Fig 4. The method consists of five steps. First the reflectance/transmittance characteristics (between 200-700 nm) of the clean uncoated quartz glass plates are determined. The quartz plates are then coated with various coating colours at different coat weights. The transmittance/ reflectance factors (between 200-700 $\mathrm{nm}$ ) of the coated quartz glass plates are then measured (\#1 in Fig 4). The standard optical properties of the base paper samples are determined 


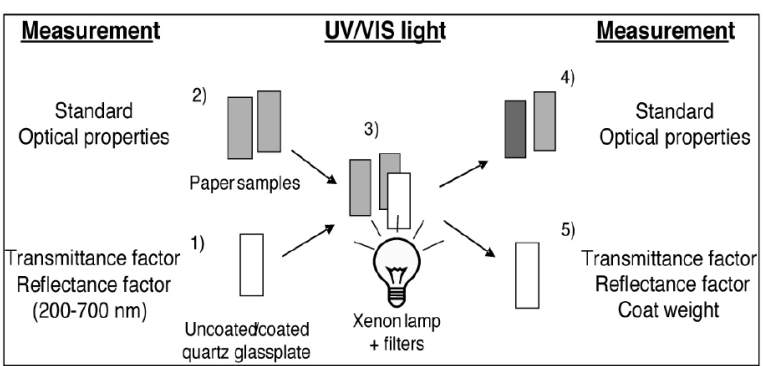

Fig 4. A schematic description of the method.

(\#2). The base paper samples are attached to the coated side of the quartz glass plates using tape, and are then put in the accelerated light-induced ageing equipment with the quartz glass plates facing the xenon lamp (\#3 in Fig 4). A reference base paper sample is also aged with no quartz plate in front of it. The optical properties of the paper samples are measured after various time periods, such as 1, 4 and 24 hours (\#4 in Fig 4). At each measuring time, the paper samples and the quartz glass plates are taken apart and then put together again. On completion of the ageing procedure, the transmittance/reflectance factors of the coated quartz glass plates are measured again; the coating is then scraped off a known area of each quartz glass plate and weighed to determine the coat weight ( $\# 5$ in Fig 4).

Fig 5 shows the reflectance factors at different wavelengths between $300-600 \mathrm{~nm}$ of coated quartz glass measured over a white background. Ground calcium carbonate (GCC), kaolin and kaolin/ $\mathrm{TiO}_{2}$ (95:5) coatings are included at different coat weights. As shown in the figure, the GCC and kaolin pigments reflect around $60-80 \%$ of the incoming light. The reflectance for kaolin is somewhat higher in the visible region but lower in the UV-region. For kaolin/ $\mathrm{TiO}_{2}$ (95:5), the reflectance is much lower in the UV-region compared to GCC, as previously reported (Johnson 1991). This phenomenon is probably due to the higher light absorption ability of the kaolin and the $\mathrm{TiO}_{2}$ (Bown 1977). High ability to absorb light in the UV-region also implies low transmittance in the same region, in case of $\mathrm{TiO}_{2}$ the high light scattering ability further contributes to a low transmittance.

Fig 6 shows the transmittance in the 300-385 nm region of coating colours containing kaolin or GCC pigments. The UV-region 300-385 $\mathrm{nm}$ was chosen since it has been proposed that the transition from photo-yellowing to photo-bleaching of lignocellulosic materials occurs at wavelengths around $385 \mathrm{~nm}$ (Nolan et al. 1945; Leary 1967; Andtbacka et al. 1989). The transition is, however, not fixed at a certain wavelength but is also affected by such factors as the wood raw material and the pulping method used (cf. Heitner 1993a).

Fig 6 shows the mean transmittance factor (300-385 $\mathrm{nm}$ ) for coatings made of kaolin or GCC at different coat weights. The absolute values of the transmittance in the UV region were low (below $0.5 \%$ ), which is explained in Fig 1. The strong dependence of the coat weight, especially for very low coat weights, was in accordance with what is predicted by the Kubelka-Munk equations for transmittance (cf. Fig 3).

The transmittance of the coating colour containing

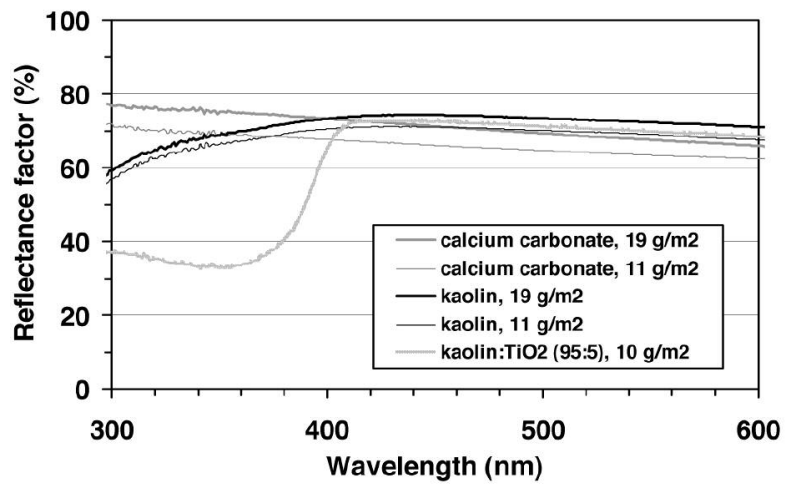

Fig 5. Reflectance factors of different pigments applied as coatings onto quartz glass measured over a white background in the wavelength region 300-600 nm. The order in the legend matches the order in which the pigments appear on the left-hand side of the figure.

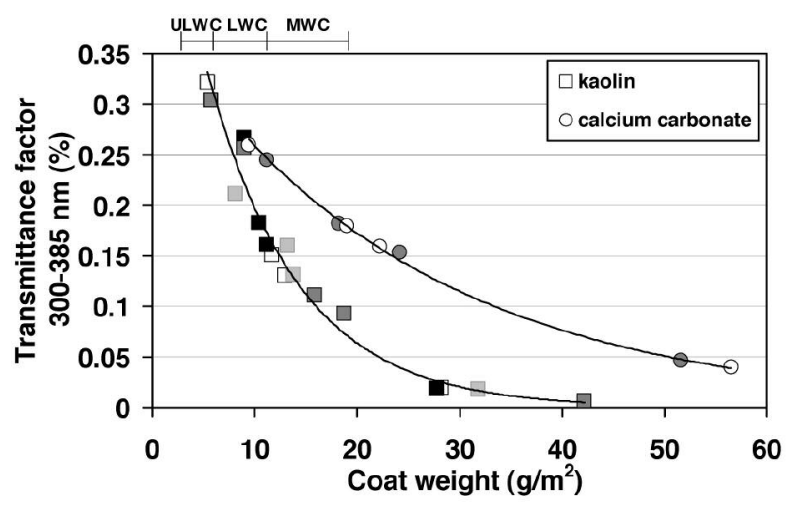

Fig 6. Mean transmittance factor in the $300-385 \mathrm{~nm}$ region of coating colours containing kaolin or ground calcium carbonate pigments. To evaluate the repeatability, the experiments were performed on four different occasions, represented by the unfilled, lightly or darkly shaded or filled symbols. ULWC $=$ ultralight-weight coating $\left(\sim 4-7 \mathrm{~g} / \mathrm{m}^{2}\right) ;$ LWC = light-weight coating $\left(\sim 7-12 \mathrm{~g} / \mathrm{m}^{2}\right) ;$ MWC = mediumweight coated $\left(\sim 13-20 \mathrm{~g} / \mathrm{m}^{2}\right)$.

kaolin pigments was lower than that of the coating colour containing calcium carbonate pigments (Fig O). This result suggests that the kaolin clay used has better photoprotecting ability than calcium carbonate, probably due to stronger light absorption. The transmittance curves in Fig 6 reflect measurements made on several different occasions, with a new coating colour being prepared each time. Despite this, the deviations are small, even in the ULWC/LWC region. The repeatability of the developed model system is thus satisfactory.

\section{Light-induced ageing of a coated $\mathrm{H}_{2} \mathrm{O}_{2}$-bleached birch CTMP}

As previously reported (Fjellström et al. 2006), hardwood high-yield pulps are more photostable than softwood high-yield pulps. Consequently, for high-quality paper grades such as fine papers, hardwood mechanical or chemimechanical pulps are therefore the preferred alternative for replacement of some of the chemical pulp in the furnish. The protecting abilities of different coating formulations were therefore evaluated on a base paper consisting of $100 \%$ hydrogen-peroxide-bleached birch CTMP.

Fig 7 shows the transmittance of light in the UV-region 300-385 nm for coating colours containing kaolin clay 


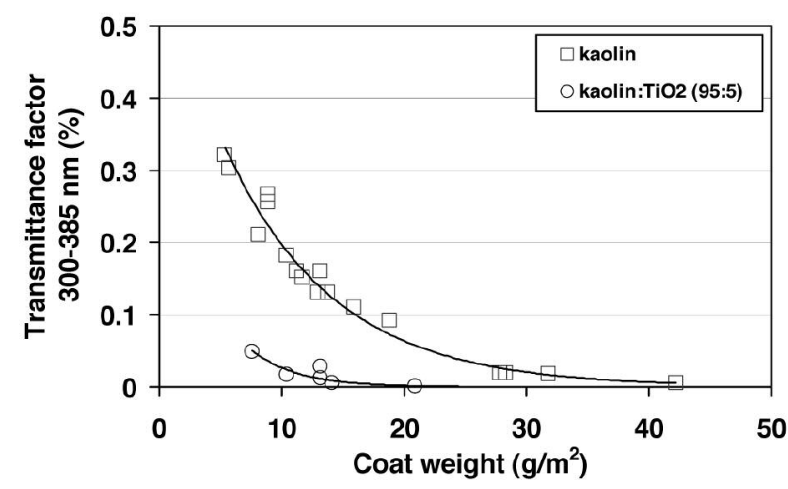

Fig 7. Transmittance in the 300-385 nm region of coating colours containing kaolin clay and the additive $\mathrm{TiO}_{2}$.

and different additives. As expected on the basis of previous research (Fossum et al. 1976; Gellerstedt et al. 1983; Johnson 1989, 1991; Ghosh et al. 2002), a small substitution of kaolin with $\mathrm{TiO}_{2}$ (5 parts) lowered the transmittance considerably. The steep transmittance factor curves at the coat weights normally used $\left(8-12 \mathrm{~g} / \mathrm{m}^{2}\right)$ suggest that an even coating layer (i.e. a smooth base paper and a proper coating procedure) will be very important when coating is used to hinder light-induced brightness reversion.

The birch CTMP base paper was placed behind the coated quartz glass plates and then subjected to accelerated light-induced ageing simulating indoor daylight, following the procedure previously described. Fig 8 shows the change in ISO brightness after 24 hours of irradiation. As can be seen in the figure, a coating colour containing 5 parts $\mathrm{TiO}_{2}$ (coat weight of about $12 \mathrm{~g} / \mathrm{m}^{2}$ ) was effective in photostabilising the CTMP paper. With this coating, the brightness loss was decreased by about $75 \%$ compared to the uncoated base paper, and by about $50 \%$ compared to the kaolin-coated base paper. This reduction in brightness loss may be less than expected from the reduced transmittance (see Fig 7) but the chromophores, responsible for the yellow colour are formed by radical reactions (Heitner 1993b; Leary 1994; Forsskåhl 2000), which means that it only takes a small amount of light to form them. It should, however, be noted that only the transmitted light between 300 and 385 $\mathrm{nm}$ was accounted for. Other wavelengths may also contribute to the light-induced brightness reversion. It must also be noted that an accelerated photo-ageing procedure was used, and that this may influence the outcome of the photo-ageing experiment (Paulsson, Parkås 2001; Fjellström et al. 2006). It was, however, evident that no substantial change in the transmission characteristics in the UV-region of the coating layers had occurred.

The study presented above demonstrates that the method presented in this paper can be used for other photostability studies. In a forthcoming work, the coating system will be used to study the photostabilising properties of different coating formulations. The method can also be used to examine the contribution of different wavelength regions to the photo-yellowing of various types of materials. Both accelerated and long-term ambient ageing methods will be employed in future studies.

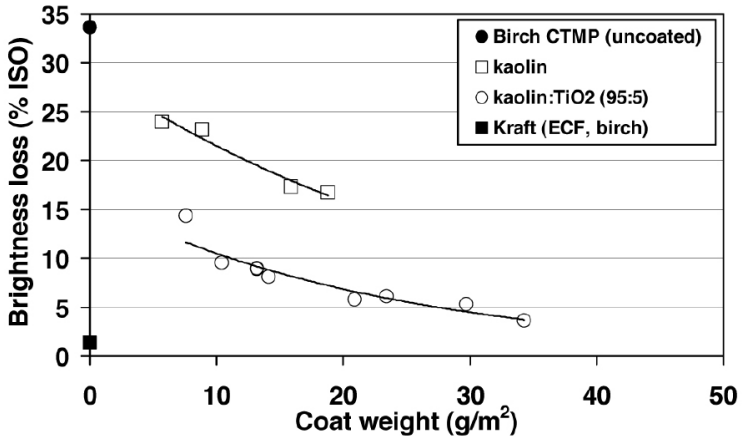

Fig 8. Change in ISO brightness after accelerated light-induced ageing for 24 hours following the procedure described in Fig 4. The ageing characteristics of uncoated $\mathrm{H}_{2} \mathrm{O}_{2}$-bleached birch CTMP and ECF-bleached birch kraft pulp are given as references.

\section{Conclusions}

The method of studying photo-yellowing presented here involves measuring the reflectance/transmittance factors of coated quartz glass plates and relating this to the photo-yellowing of papers placed behind these plates. This method has been shown to give highly reliable results even for low coat weights $\left(<10 \mathrm{~g} / \mathrm{m}^{2}\right)$. Thus this method has the potential to be a valuable tool for photoyellowing studies as well as for optimisation of coating colour formulations for various paper grades.

\section{Acknowledgements}

The authors would like to thank SCA Graphic Research AB, Sundsvall for valuable support. The financial support of the Fibre Science and Communication Network (FSCN), EU Objective 1, Region of South Forest Counties, the Knowledge Foundation (KK stiftelsen) and the Swedish Energy Agency are gratefully acknowledged.

\section{Literature}

Agnemo, R., Francis, R.C., Alexander, T.C. and Dence, C.W. (1991): Studies on the mechanism of the photo yellowing of bleached mechanical and chemimechanical pulps. III. The role of hydroxyl radicals, Holzforschung, 45:(Suppl.), 101.

Andtbacka, A., Holmbom, B. and Gratzl, J.S. (1989): Factors influencing lightinduced yellowing and bleaching of spruce groundwood, 5th Int. Symp. Wood Pulp. Chem., Raleigh, NC, USA, May 22-25, Vol. 1, 347-351.

Bourgoing, S. and Robert, S. (1997): Use of fluorescent whitening agents against light-induced colour reversion of high yield pulps, 9th Int. Symp. Wood Pulp. Chem., Montreal, Que, Canada, June 9-12, 10.1-10.4.

Bourgoing, S., Leclerk, E., Martin, P. and Robert, S. (2001): Use of fluorescent whitening agents to inhibit light-induced colour reversion of unbleached mechanical pulps, J. Pulp Paper Sci. 27(7), 240-244.

Bown, R. (1997): A review of the influence of pigments on papermaking and coating. Fundamentals of papermaking materials, 11th Fundamental Res. Symp, Cambridge, UK, September 21-26, Editor C.F. Baker, Pira international, Leatherhead,Vol. 1, 83-138.

Cole, B.J.W., Wang, J. and Fort, R.C. (2000): The bleaching and photo stabilization of high-yield pulp by sulfur compounds. II. Reaction of glycol mercaptoesters with model quinones, J. Wood. Chem. Technol. 20(1), 1-17.

Davidson, R.S. (1996): The photodegradation of some naturally occurring polymers, J. Photochem. Photobiol. B 33(1), 3-25.

Ek, M., Lennholm, H. and Iversen, T. (1990): A comment on the effect of carbonyl groups on the light-induced reversion of groundwood pulp, Nord. Pulp Paper Res. J. 5(4), 159-160.

Ek, M., Lennholm, H., Lindblad, G. and Iversen, T. (1992): A study on the mechanism of the photo-yellowing of partially acetylated groundwood pulps, Nord. Pulp Paper Res. J. 7(3), 108-112. 
El-Sadi, H., Yuan, Z., Esmail, N. and Schmidt, J. (2002): Factors affecting the inhibition of light-induced yellowing of a coated BTMP paper, J. Pulp Paper Sci. 28(12), 400-405.

Fjellström, H., Höglund, H. and Paulsson, M. (2007): Light-induced yellowing of mechanical and chemimechanical pulp sheets: Influence of wood raw material, process and ageing method, Nord. Pulp Paper Res. J. 22(1), 117-123.

Forsskåhl, I. (2000): Brightness reversion, In: Forest Products Chemistry, Edited by P. Stenius. Fapet Oy, Helsinki, Finland, pp. 278-332.

Fossum, T., Lindahl, A., Rudström, L. and Smedman, L. (1976): High grade graphic paper from mechanical pulp, Pulp Paper Can. 77(2), 53-55.

Gellerstedt, G., Pettersson, I., and Sundin; S. (1983): Light-induced and heatinduced yellowing of mechanical pulps, Svensk Papperstidning, 86(15), R157R163.

Ghosh, T., Cogswell, D., Cunningham, A. and Raue, D. (2002): Inhibition of brightness reversion in coated groundwood sheets: Effect of coatweight, application method and coating ingredients, TAPPI Coating Conf., Orlando, FL, USA, May 5-8, 11 pp. (CD-ROM).

Gratzl, J.S., (1985): Lichtinduzierte Vergilbung von Zellstoffen - Ursachen und Verhütung, Papier, 39(10A), V14-23.

Heitner, C. (1993a): Inhibition of light-induced yellowing of lignin-containing paper, In: Photochemistry of Lignocellulosic Materials, Edited by C. Heitner and J.C. Scaiano, ACS Symposium Series 531, Washington, DC, USA, pp. 192-204.

Heitner, C. (1993b): Light-induced yellowing of wood-containing papers: An evolution of the mechanism, In: Photochemistry of Lignocellulosic Materials, Edited by C. Heitner and J.C. Scaiano, ACS Symposium Series 531, Washington, DC, USA, pp. 2-25.

Janson, J. and Forsskåhl, I. (1989): Colour changes in lignin-rich pulps on irradiation by light, Nord. Pulp Paper Res. J. 4(3), 197-205.

Janson, J. and Forsskåhl, I. (1996): Polytetrahydrofuran: A polymer that counteracts colour reversion, Nord. Pulp Paper Res. J. 11(1), 10-14.

Johnson, R.W. (1989): Brightness stability of mechanical pulps. Relating laboratory data to performance, Tappi J. 72(12), 181-187.

Johnson, R.W. (1991): CTMP in fine papers: On-machine surface treatments for improved brightness stability, Tappi J. 74(5), 209-217.

Karipidis, C. (1994): Determination of the optical properties of a layer (sheet) by the two background method, Licentiate thesis, The Royal Institute of Technology (KTH), Stockholm, Sweden.

Kringstad, K. (1969): Degradation of wood and high-yield pulps by light, Tappi, 52(6), 1070-1074.

Lanzalunga, 0. and Bietti, M. (2000): Photo- and radiation chemical induced degradation of lignin model compounds, J. Photochem. Photobiol. B 56(2-3), 85108.

Leary, G.J. (1967): The yellowing of wood by light, Tappi, 50(1), 17-19.

Leary, G.J. (1968): The yellowing of wood by light: Part 2, Tappi, 51(6), 257-260.

Leary, G.J. (1994): Recent progress in understanding and inhibiting the light- induced yellowing of mechanical pulps, J. Pulp Paper Sci. 20(6), J154-J160. Lin, S.Y. and Kringstad, K.P. (1970): Stabilization of lignin and lignin model compounds to photodegradation, Tappi, 53(9), 1675-1677

Lindblad, G., Iversen, T., Bergenblad, H. and Rigdahl, M. (1989): Light scattering ability as a tool to protect paper and board against photo-oxidation, Nord. Pulp Paper Res. J. 4(4), 253-257.

Nolan, P., Van den Akker, J.A. and Wink, W.A. (1945): The "fading" of groundwood by light, Paper Trade J. 121(11), 33-37.

Paulsson, M. and Ragauskas, A.J. (1998a): Chemical modification of lignin-rich paper. Part 7. Photostabilizing high-brightness aspen CTMP by combining various classes of additives and acetylation, Nord. Pulp Paper Res. J. 13(2), 124-131.

Paulsson, M. and Ragauskas, A.J. (1998b): Chemical modification of lignin-rich paper. Part 8. Effect of light source on the accelerated light-induced yellowing of untreated and acetylated high-yield pulps, Nord. Pulp Paper Res. J. 13(2), 132142.

Paulsson, M. and Parkås, J. (2000): Chemical modification of chemithermomechanical pulps part 1: Mechanical, optical, and aging properties of propionylated spruce CTMP, J. Wood. Chem. Technol. 20(2), 205-224.

Paulsson, M. and Parkås, J. (2001): Long-term natural aging of untreated and chemically modified high-yield pulps, 11th Int. Symp. Wood Pulp. Chem., Nice, France, June 11-14, Vol. 2, 227-230.

Paulsson, M. and Simonson, R. (2002): Acetylation of lignin and photostabilization of lignin-rich mechanical wood pulp and paper, In: Chemical Modification, Properties, and Usage of Lignin, Edited by T.Q. Hu, Kluwer Academic/Plenum Publishers, New York, NY, USA, pp. 221-245.

Ragauskas, A.J., Allison, L., Lucia, L.A. and Li, C. (2001): Brightness reversion of mechanical pulps XIV: Application of FWAs for high-brightness high-yield pulps, Solutions/Tappi J. 84(11), 1-11.

Rohringer, P. and Fletcher, I. (1996): Spectral properties of paper treated with fluorescent whitening agents and the effects of agent application, TAPPI Coating Conf., Nashville, TN, USA, May 19-22, 239-251.

Rundlöf, M. and Bristow, J.A. (1997): A note concerning the interaction between light scattering and light absorption in the application of the Kubelka-Munk equations, J. Pulp Paper Sci. 23(5), 220-223.

Schmidt, J. A. and Heitner, C. H. (1991): Light-induced yellowing of mechanical and ultra-high yield pulps. Part 1. Effect of methylation, $\mathrm{NaBH}_{4}$ reduction and ascorbic acid on chromophores formation, J. Wood. Chem. Technol. 11(4), 397418.

Yuan, Z., Schmidt, J., Gilbert, D., Aspler, J., Heitner, C, Cunkle, G. and Ghosh, T. (2003): Improving the brightness stability of a machine coated mechanical paper: A mill trial, Int. Mech. Pulp. Conf., Québec City, Québec, Canada, June 2-5, 115-123.

Manuscript received July 12, 2006 Accepted May 2, 2007 